\title{
Exposure to the plasticizer di(2-ethylhexyl) terephthalate (DEHTP) in Portuguese children - Urinary metabolite levels and estimated daily intakes
}

\author{
Frederik Lessmann ${ }^{\mathrm{a}}$, Luísa Correia-Sáb,c ${ }^{\text {, Conceição Calhau }}{ }^{\mathrm{c}}$, Valentina F. Domingues ${ }^{\mathrm{b}}$, \\ Tobias Weiss ${ }^{\mathrm{a}}$, Thomas Brüning ${ }^{\mathrm{a}}$, Holger M. Koch ${ }^{\mathrm{a}, *}$ \\ a Institute for Prevention and Occupational Medicine of the German Social Accident Insurance, Institute of the Ruhr-Universität Bochum (IPA), Bürkle-de-la-Camp-Platz 1, \\ 44789 Bochum, Germany \\ b REQUIMTE/LAQV-GRAQ, Instituto Superior de Engenharia do Porto do Instituto Politécnico do Porto, Rua Dr. António Bernardino de Almeida, 431, 4200-072 Porto, \\ Portugal \\ ${ }^{c}$ Centro de Investigação em Tecnologias e Sistemas de Informação em Saúde (CINTESIS), Centro de Investigação Médica, $2^{\circ}$ piso, edif. Nascente, Faculdade de Medicina da \\ Universidade do Porto, Rua Dr Plácido da Costa s/n, 4200-450 Porto, Portugal
}

\author{
Keywords: \\ Di(2-ethylhexyl) terephthalate \\ Plasticizer \\ Human biomonitoring \\ Children \\ Urine \\ Daily intake
}

\begin{abstract}
A B S T R A C T
Classical ortho-phthalate plasticizers are, due to their endocrine disrupting potency and reproductive toxicity, increasingly replaced by alternative plasticizers. Di(2-ethylhexyl) terephthalate (DEHTP) is one of these substitutes. In this study, we investigated DEHTP exposure in 107 Portuguese children (4-17 years old) by analyzing specific DEHTP metabolites in their urine using a newly developed LC-MS/MS method. We could detect the major, specific DEHTP metabolite mono(2-ethyl-5-carboxypentyl) terephthalate (5cx-MEPTP) in $100 \%$ of the samples with levels above the limit of quantification in $96 \%$ of the samples (median concentration $4.19 \mu \mathrm{g} / \mathrm{L}$; 95th percentile $26.4 \mu \mathrm{g} / \mathrm{L}$; maximum $3400 \mu \mathrm{g} / \mathrm{L}$ ). Other minor DEHTP metabolites (5OH-MEHTP, 5oxo-MEHTP and 2cx-MMHTP) were detected at lower rates and levels. Daily DEHTP intakes calculated from urinary 5cx-MEPTP levels were generally far below the tolerable daily intake (TDI) of $1000 \mu \mathrm{g} / \mathrm{kg} \mathrm{bw} / \mathrm{d}$ (median $0.67 \mu \mathrm{g} / \mathrm{kg} \mathrm{bw} / \mathrm{d}$; 95 th percentile $6.25 \mu \mathrm{g} / \mathrm{kg}$ bw/d; maximum $690 \mu \mathrm{g} / \mathrm{kg}$ bw $/ \mathrm{d}$ ). However, for one child the biomarker-derived health-based guidance value (HBM-I value) for 5cx-MEPTP of $1800 \mu \mathrm{g} / \mathrm{L}$ was exceeded by about a factor of two. Levels of 5cx-MEPTP and calculated daily DEHTP intakes were higher in normal/underweight children who nourished on their usual diet compared to overweight/obese children who received nutritional guidance with fresh and unprocessed food $(\mathrm{p}=0.043$ and $\mathrm{p}<0.001$ respectively). This indicates to processed and fatty foodstuff as a major source of DEHTP exposure. Additionally, we found children of lower age having higher DEHTP intakes $(\mathrm{p}=0.045)$. Again, foodstuff as a major DEHTP source, together with other child specific DEHTP sources such as mouthing of toys or ingestion of dust might be contributing factors. With the present study, we provide a first data set on the omnipresent DEHTP exposure in children. So far, general levels of DEHTP exposure seem no cause for concern. However, due to the increasing use of DEHTP as an orthophthalate substitute, possible increasing exposures in the future should be followed closely.
\end{abstract}

\section{Introduction}

Di(2-ethylhexyl) terephthalate (DEHTP), CAS Registry No. 6422-862, a structural isomer of Di(2-ethylhexyl) phthalate (DEHP), is used as an alternative plasticizer for polymers like polyvinylchloride (PVC). Lately, some "classic" PVC plasticizers such as the high molecular weight (HMW) phthalate DEHP, are under scrutiny due to their proven reproductive toxicity and anti-androgenic activity in rodents. These effects, also known as the "phthalate syndrome" are mainly caused by inhibition of fetal testicular testosterone production during sexual differentiation leading to reproductive tract malformations, reduced fertility and/or influences on the male phenotype (shortening of the anogenital distance and areola/nipple retention) (Foster, 2006, Boberg et al., 2011, Kilcoyne et al., 2014). As a consequence, DEHP has been classified as toxic to reproduction category $1 \mathrm{~B}$ according to the European Regulation on classification, labelling and packaging of substances (EU CLP Regulation) (European Parliament, 2008). Since 1999, DEHP, di(isononyl) phthalate (DiNP), di(isodecyl) phthalate (DiDP) and di(n-octyl) phthalate (DnOP) have been banned or restricted in sensitive applications such as toys or childcare articles

\footnotetext{
* Corresponding author.

E-mail address: koch@ipa-dguv.de (H.M. Koch).
} 
according to Regulation (EC) No 1907/2006, Annex XVII, 51/52. From February 2015 on (REACH sunset date), DEHP must not be placed on the EU market any more, being listed in Annex XIV of the REACH regulation EC No 1907/2006 (European Commission, 2006). However, since plasticizers are still indispensable in many applications, alternative plasticizers like DEHTP, with advantageous toxicological profiles (Gray et al., 2000, Furr et al., 2014) and no use restrictions are gaining importance in the worldwide plasticizer market. In the year 2002 the Western European consumption volume of DEHTP amounted to a total of $2000 \mathrm{mt}$. Consumption rose to $100,000 \mathrm{mt}$ in 2014. Predictions for the year 2019 estimate a total production of about 135,000 mt, clearly reflecting the growing importance of DEHTP as an alternative plasticizer (Malveda et al., 2015).

Typical effects associated with DEHP toxicity have not been observed for DEHTP (Gray et al., 2000). Furr et al. (2014) reported no disruption of fetal testosterone synthesis or altered testis gene expression in rats in their Fetal Phthalate Screen (FPS). Toxicological studies with DEHTP reported no or very weak peroxisome proliferating potential in rats (Barber and Topping, 1995, Topping et al., 1987) indicated by increased relative liver weight at the highest dietary DEHTP content of $2.5 \%$. However, the authors concluded, that relative liver weight might have been increased only due to reduced feed consumption. The European Food Safety Authority (EFSA) evaluated DEHTP (EFSA, 2008) and derived a tolerable daily intake (TDI) of $1000 \mu \mathrm{g} / \mathrm{kg}$ bw/d based upon a 2-year combined toxicity/carcinogenicity study (Deyo, 2008); the most sensitive end points observed were effects on the retina and nasal turbinates. Recently, the German Human Biomonitoring Commission has published new HBM values for emerging chemicals, DEHTP being one of them (Apel et al., 2016). The HBMI value for the main specific urinary metabolite mono(2-ethyl-5carboxypentyl) terephthalate (5cx-MEPTP) in urine, above which a possible adverse health effect cannot be excluded anymore, was derived to be $1800 \mu \mathrm{g} / \mathrm{L}$ based on the endpoint "effects on the retina" as observed by Deyo (2008).

According to Commission Regulation (EU) Regulation No 10/2011, DEHTP is approved as an additive in food contact materials with a specific migration limit of $60 \mathrm{mg} / \mathrm{kg}$ food (European Commission, 2011). Together with the gradually increasing production of DEHTP, a widespread exposure of the general population to DEHTP has to be expected. Human biomonitoring has been proven to be an ideal tool to assess population exposure to phthalates or other plasticizers (Silva et al., 2003, Koch et al., 2004, 2005, 2013a, 2013b, Koch and Angerer, 2012, KasperSonnenberg et al., 2014, Schütze et al., 2014). A pilot biomonitoring study with German adults already indicated an omnipresent exposure of non-occupationally exposed individuals to DEHTP (Lessmann et al., 2016a). More than $90 \%$ of the urine samples analyzed contained DEHTP metabolites above the limit of quantification. With this study we intend to broaden the knowledge on DEHTP exposure to Portugal, another country in the European Union. Furthermore, previous studies have reported that the plasticizer body burden of children can be higher, compared to adults (Koch and Angerer, 2007, Kasper-Sonnenberg et al., 2014, Den Hond et al., 2015, Cutanda et al., 2015, Fromme et al., 2016). Thus, investigating children in this study was of additional interest. Due to the special composition of the children population of this study (obese children under nutritional guidance vs. normal weight children on their usual diet) another aim was to investigate possible differences in DEHTP exposures among these children.

\section{Methods}

\subsection{Subjects and urine specimens}

The present study is part of an ongoing study investigating exposure of obese/overweight and regular weight children to certain environmental chemicals. The initial aim of this project was the determination of exposure to several suspected or confirmed (predominately persis- tent) endocrine disruptors and/or obesogens. Due to the ongoing substitution process and considering new regulatory requirements, plasticizers and plasticizer substitutes like DINCH and DEHTP have subsequently been added to the list of substances of interest. The study design itself has not been created with relevance to DEHTP. Originally, 112 Portuguese children donated first morning urine voids, and their complete anthropometric data (gender, age, height, and weight) were recorded. Samples were collected in the years 2014/2015 in the pediatric appointment at Hospital de S. João, and several local schools in the regions of Oporto and Aveiro, located in the north and central region of Portugal. At the time of analysis of the present study, sample material of 107 children, aged 4-17 years, was left. The available samples were divided into two groups according to the respective children's body mass index (BMI). Group 1 consisted of 39 normal/ underweight children, without any known associated diseases, on a usual diet without further nutritional guidance. Group 2 consisted of 68 overweight/obese children, without other known associated diseases, receiving specific nutritional guidance with fresh and unprocessed food (meaning fresh fruits and vegetables, whole grains, low-fat and nonfat dairy products, beans, fish, and lean meat). The children's nutritional status was assessed according to the World Health Organization growth charters (WHO, 2007). Body weight and BMI differed significantly ( $\mathrm{p}<0.05$ ) between the two investigated study groups, whereas age, gender, height and urinary creatinine did not $(\mathrm{p}>0.05)$. A detailed description of the study population is given in Table 1 .

\subsection{Chemical analysis}

The on-line HPLC-MS/MS method used for quantification of specific urinary DEHTP metabolites has been described in detail by Lessmann et al. (2016a). In short, to each urine sample aliquot, ammonium acetate buffer and internal standard solution were added. After enzymatic hydrolysis with $\beta$-glucuronidase from E. coli K12 (arylsulfatase free), the $\mathrm{pH}$ was adjusted with acetic acid and samples were frozen over night to precipitate proteins. After thawing, samples were centrifuged and the supernatant was injected into an Agilent Technologies LC 1260 system (Agilent 1260 autosampler, two Agilent 1260 binary pumps) coupled to an $\mathrm{AB}$ Sciex 4500 triple quadrupole mass spectrometer in negative ionization mode. On-line SPE column assembly, HPLC gradient and MS/MS conditions remain as described in Lessmann et al. (2016a). The limit of quantification (LOQ) was $0.2 \mu \mathrm{g} / \mathrm{L}$ for mono(2-ethyl-5-carboxypentyl) terephthalate (5cx-MEPTP) and mono(2-ethyl-5-oxohexyl) terephthalate (5oxo-MEHTP), $0.3 \mu \mathrm{g} / \mathrm{L}$ for mono(2-ethyl-5-hydroxyhexyl) terephthalate (5OH-MEHTP), and $0.4 \mu \mathrm{g} / \mathrm{L}$ for mono[2-(carboxymethyl)hexyl] terephthalate (2cxMMHTP). Urinary creatinine concentrations were determined according to a modified Ja ffé method (Jaffe, 1886) with an Olympus AU5400 ${ }^{\circledR}$ Chemistry Analyzer.

Table 1

General characteristics of the investigated study population.

\begin{tabular}{|c|c|c|c|}
\hline $\begin{array}{l}\text { Population } \\
\text { characteristics }\end{array}$ & $\begin{array}{l}\text { Group } 1 \\
\text { Normal/under } \\
\text { weight, usual } \\
\text { diet }\end{array}$ & $\begin{array}{l}\text { Group } 2 \\
\text { Overweight/obese, } \\
\text { nutritional guidance }\end{array}$ & Total \\
\hline $\mathrm{n}$ & 39 & 68 & 107 \\
\hline Age (years) median & 11.0 & 9.0 & 10.0 \\
\hline Gender (\%) & $\begin{array}{l}44 \% \text { female, } \\
56 \% \text { male }\end{array}$ & $56 \%$ female, $44 \%$ male & $\begin{array}{l}49 \% \text { female, } \\
51 \% \text { male }\end{array}$ \\
\hline Height $(\mathrm{cm})$ median & 143 & 142 & 142 \\
\hline $\begin{array}{l}\text { Body weight }(\mathrm{kg}) \\
\text { median }\end{array}$ & 35 & 46 & 45 \\
\hline $\begin{array}{l}\text { BMI }\left(\mathrm{kg} / \mathrm{m}^{2}\right) \\
\text { median }\end{array}$ & 17.1 & 24.7 & 22.3 \\
\hline $\begin{array}{l}\text { Creatinine }(\mathrm{g} / \mathrm{L}) \\
\text { median }\end{array}$ & 0.87 & 0.96 & 0.93 \\
\hline
\end{tabular}




\subsection{Daily intake estimation}

For the estimation of daily intakes based on 5cx-MEPTP levels in spot urine samples of children, we applied the approach published by Koch and Angerer (2007) and Wittassek et al. (2007) for the plasticizers Di(n-butyl) phthalate (DnBP), butyl-benzyl phthalate (BBzP) and DEHP. In short, the calculation is based on the creatinine related metabolite concentration, combined with reference values for the 24-hour creatinine excretion in children according to Remer et al. (2002). The daily intake in $\mu \mathrm{g} / \mathrm{kg}$ bw/d is calculated by the following equation modified according to previous daily intake calculations (David, 2000, Kohn et al., 2000, Koch et al., 2003a, 2003b, Schütze et al., 2014):

$$
\begin{aligned}
\operatorname{DI}\left(\mu \mathrm{g} / \mathrm{kg}_{\mathrm{bw}} / \mathrm{day}\right)= & \frac{\mathrm{UE}_{5 \mathrm{cx}-\mathrm{MEPTP}}\left(\mu \mathrm{mol} / \mathrm{g}_{\text {crea }}\right) \times \mathrm{CE}_{\text {smoothed }}(\mathrm{g} / \text { day })}{\mathrm{F}_{\mathrm{UE}} \times \mathrm{bw}(\mathrm{kg})} \\
& \times \operatorname{MW}_{\operatorname{DEHTP}}(\mathrm{g} / \mathrm{mol})
\end{aligned}
$$

$\mathrm{UE}_{5 \mathrm{cx}-\mathrm{MEPTP}}$ is the concentration of $5 \mathrm{cx}$-MEPTP in the respective urine sample in micromole per gram creatinine. $\mathrm{CE}_{\text {smoothed }}$ is the gender- and body height dependent 24-hour reference value for the creatinine excretion of healthy Caucasian children (aged 4-17 years) in gram creatinine per day according to Remer et al. (2002). The urinary excretion factor $\mathrm{F}_{\mathrm{UE}}$ represents the percentage of excreted metabolite 5 cx-MEPTP, relative to the dose of the parent compound DEHTP. We used the $\mathrm{F}_{\mathrm{UE}} 0.13$ as determined in an oral human metabolism study with three healthy male volunteers (Lessmann et al., 2016b), meaning that $13 \%$ of the orally administered dose of DEHTP were recovered as 5 cx-MEPTP in urine. $\mathrm{MW}_{\text {DEHTP }}$ is $390.56 \mathrm{~g} / \mathrm{mol}$, the molecular weight of DEHTP.

\subsection{Statistical analysis}

Statistical analysis was conducted with IBM SPSS statistics 23. Boxplots were generated with OriginPro 2016. DEHTP metabolite concentrations were calculated in $\mu \mathrm{g} / \mathrm{L}$ and creatinine adjusted values in $\mu \mathrm{g} / \mathrm{g}$ creatinine. Metabolite concentrations below the LOQ were substituted with LOQ/2 (Hornung and Reed, 1990). For associations between metabolite levels, the bivariate correlation Spearman's rho was used. To investigate associations between metabolite levels or daily intake and gender, body weight or age, we applied the Mann-Whitney$U$ test. For the statistical analysis, age groups were categorized according to European guidelines for clinical studies with pediatric patients (ICH, 2000). By use of the Jonckheere-Terpstra test (Jonckheere, 1954), we investigated a possible age dependent trend in the daily intake of DEHTP. The Jonkcheere-Terpstra test is a nonparametric test for independent samples, comparable to the Kruskal-Wallis test. In contrast to the Kruskal-Wallis test, the JonckheereTerpstra test analyzes an existence of a trend among groups.

\section{Results and discussion}

\subsection{Metabolite levels}

The main specific DEHTP metabolite 5cx-MEPTP was detectable in all 107 samples analyzed with levels above the limit of quantification in
$96 \%$ of the samples. The median concentration was $4.19 \mu \mathrm{g} / \mathrm{L}$, the 95 th percentile $26.4 \mu \mathrm{g} / \mathrm{L}$, and the maximum concentration $3400 \mu \mathrm{g} / \mathrm{L}$. The other metabolites were detected at lower rates and concentrations. Detailed results including creatinine adjusted concentrations are shown in Table 2. The metabolic pattern reflected in the median and 95th percentile metabolite concentrations is comparable to the pattern observed in the oral metabolism study with three male volunteers performed by our group (Lessmann et al., 2016b). 5cx-MEPTP was clearly the dominant specific urinary metabolite followed by $5 \mathrm{OH}$ MEHTP and 5oxo-MEHTP at concentrations about an order of magnitude lower. 2cx-MMHTP was detected only in those urine samples with highest levels of the other DEHTP metabolites.

We observed significant correlations between all three major DEHTP metabolites (see Fig. 1). Similar correlations have also been reported for the specific, oxidized metabolites of DEHP (Koch et al., 2003a, 2003b, Barr et al., 2003) or the metabolites of the phthalate substitute DINCH (Schütze et al., 2012, 2017). Obviously, the correlation between 5cx-MEPTP and 5oxo-MEHTP was weakest among the three oxidized DEHTP metabolites. From the human metabolism study we know, that parameters of elimination kinetics differ the most between 5cx-MEPTP $\left(\mathrm{t}_{\max }=4.2 \mathrm{~h}\right)$ and 5oxo-MEHTP $\left(\mathrm{t}_{\max }=5.2 \mathrm{~h}\right)$ (Lessmann et al., 2016b). Likewise to DEHP or DINCH, correlations were strongest for those metabolites with similar behavior in elimination kinetics.

We can compare the metabolite levels of this study with the, so far, only other human biomonitoring study on DEHTP with metabolite levels in 34 German adults from the year 2014 (Lessmann et al., 2016a). Compared to the median 5cx-MEPTP level of $0.90 \mu \mathrm{g} / \mathrm{L}$ in German adults, the median level in Portuguese children $(4.19 \mu \mathrm{g} / \mathrm{L})$ is approximately 5-times higher. The maximum concentration of 5cx-MEPTP $(38.7 \mu \mathrm{g} / \mathrm{L}$ vs. $3400 \mu \mathrm{g} / \mathrm{L})$ is almost 100-times higher in the Portuguese children. For the other metabolites a comparison is difficult because of their rather low detection rates in the German adults. Previous studies have already reported children being additionally exposed to plasticizers, due to behavioral differences and an increased food uptake (Wittassek et al., 2007, Frederiksen et al., 2013, Cutanda et al., 2015, Myridakis et al., 2015, Fromme et al., 2016). In the European DEMOCOPHES study (Černá et al., 2015, Den Hond et al., 2015) children consistently excreted higher levels of DEHP metabolites compared to their mothers, both in Germany and Portugal. At the same time, DEHP metabolite excretions were generally higher in Portugal than in Germany. Similar country and age specific differences in exposure can thus be assumed also for DEHTP as a direct substitute of DEHP and explain the 5-times higher median metabolite levels in Portuguese children compared to German adults.

In a more detailed investigation of the Portuguese children we checked for possible influences of gender, study group (normal-/ underweight children on usual diet vs. overweight/obese children on nutritional guidance), and age on urinary 5cx-MEPTP concentrations (both in $\mu \mathrm{g} / \mathrm{L}$ and $\mu \mathrm{g} / \mathrm{g}$ creatinine). The results are shown in Table 3 and depicted as boxplots in Fig. 2.

We did not evaluate the other DEHTP metabolites, due to their considerably lower urinary concentrations and detection rates. We found no influence of gender on urinary 5cx-MEPTP concentrations in $\mu \mathrm{g} / \mathrm{L}$ and $\mu \mathrm{g} / \mathrm{g}$ creatinine. However, we observed significantly higher

Table 2

\begin{tabular}{|c|c|c|c|c|c|c|c|c|}
\hline \multirow[t]{2}{*}{ Metabolite } & \multirow[t]{2}{*}{$\mathrm{LOQ}[\mu \mathrm{g} / \mathrm{L}]$} & \multirow[t]{2}{*}{$>$ LOQ [\%] } & \multicolumn{3}{|c|}{ Concentration $[\mu \mathrm{g} / \mathrm{L}]$} & \multicolumn{3}{|c|}{ Concentration $[\mu \mathrm{g} / \mathrm{g}$ creatinine $]$} \\
\hline & & & Median & 95th P. & Max. & Median & 95th P. & Max. \\
\hline 5ОН-МЕНТР & 0.3 & 67 & 0.45 & 2.86 & 182 & 0.49 & 4.01 & 209 \\
\hline 5oxo-MEHTP & 0.2 & 58 & 0.27 & 2.18 & 60.7 & 0.31 & 3.28 & 69.6 \\
\hline 5cx-MEPTP & 0.2 & 96 & 4.19 & 26.4 & 3400 & 3.88 & 35.0 & 3900 \\
\hline 2cx-ММНТР & 0.4 & 7 & $<\mathrm{LOQ}$ & 0.57 & 67.9 & $<\mathrm{LOQ}$ & 1.07 & 77.9 \\
\hline
\end{tabular}

Results of the human-biomonitoring study with 107 Portuguese children, aged 4-17. 

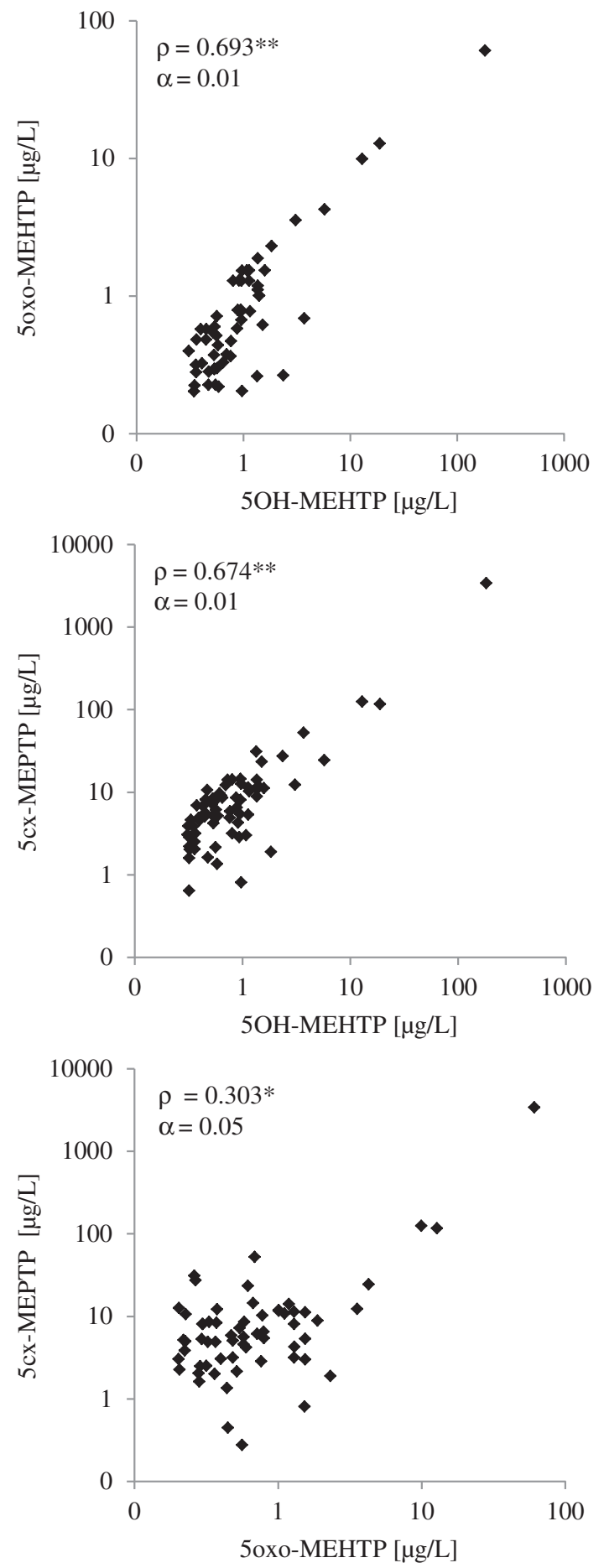

Fig. 1. Spearman-correlations between urinary concentrations of the specific DEHTP metabolites 5OH-MEHTP, 5cx-MEPTP and 50xo-MEHTP; only values above LOQ are depicted. $\rho=$ Spearman's rank correlation coefficient, $\alpha=$ level of significance.

urinary 5cx-MEPTP concentrations in the group of normal weight children compared to the group of overweight children. This significant difference (with obese children exhibiting lower exposures to DEHTP than regular weight children) stands in some contrast to previous (epidemiological) studies on phthalate plasticizers that found e.g. DEHP body burden to be associated with an increase in body weight and BMI (Trasande et al., 2013, Buser et al., 2014, Hou et al., 2015, Yaghjyan et al., 2015, Kim et al., 2016). However, as part of the study design, the group of overweight/obese children received nutritional guidance with unprocessed and fresh food, whereas the regular weight children fed on their usual diet. Several studies have already identified certain groups of food as possible sources of DEHP exposure (Sathyanarayana et al., 2013, Mervish et al., 2014). Additionally, exposure to DEHP can be reduced by dietary interventions (Rudel et al., 2011, Koch et al., 2013a, 2013b, Ackerman et al., 2014). Since DEHTP is a direct substitute for DEHP, we thus assume that the influencing factor resulting in significantly lower urinary levels of 5cx-MEPTP in the overweight children is their style of diet. In regard to age, we found elevated 5cx-MEPTP concentrations in the younger children only after creatinine adjustment and not for unadjusted levels in $\mu \mathrm{g} / \mathrm{L}$. Creatinine excretion is known to be lower in younger children (Barr et al., 2005), which in turn drives creatinine adjusted concentrations to higher values in younger children compared to older children. The significance of this effect in terms of actual exposure doses is investigated in more detail in the following daily intake section.

\subsection{Daily intakes}

We calculated the daily DEHTP intakes, based on the urinary $5 \mathrm{cx}$ MEPTP concentrations, taking account of body height and gender based reference values for urinary creatinine excretion (Remer et al., 2002; Koch and Angerer, 2007). For the study population as a whole, the median daily DEHTP intake was $0.67 \mu \mathrm{g} / \mathrm{kg}$ bw/d (95th percentile $6.25 \mu \mathrm{g} / \mathrm{kg}$ bw/d; maximum $690 \mu \mathrm{g} / \mathrm{kg}$ bw/d). Detailed results for the different subgroups (gender, study group, age) are shown in Table 4 and depicted as boxplots in Fig. 3 .

We could not observe any gender specific differences in daily DEHTP intakes. Actually, boys and girls had very similar median daily DEHTP intakes (0.62 vs. $0.67 \mu \mathrm{g} / \mathrm{kg}$ bw/d). However, the children who received specific nutritional guidance, had about 2.5 fold lower daily intakes compared to the children who fed on their usual diet $(0.40 \mu \mathrm{g} /$ $\mathrm{kg}$ bw/d vs. $1.01 \mu \mathrm{g} / \mathrm{kg}$ bw/d; $\mathrm{p}<0.001)$. In terms of absolute intakes (calculated as a product of each child's estimated daily intake and the respective body weight), findings were pointing in the same direction with children on nutritional guidance having lower absolute intakes compared to children feeding on a usual diet $(23.1 \mu \mathrm{g} / \mathrm{d}$ vs. $32.4 \mu \mathrm{g} / \mathrm{d}$ respectively). These findings confirm previous assumptions that the children's style of diet is an important factor influencing DEHTP exposure. Furthermore, calculated median daily DEHTP intakes of the younger children, 4-11 years of age, were about 2 fold higher compared to older children, $12-17$ years of age $(0.71$ vs. $0.36 \mu \mathrm{g}$ / $\mathrm{kg}$ bw/d; $\mathrm{p}=0.045)$.

To further investigate age dependency of DEHTP exposure, we divided the children into six smaller age groups and applied the Jonckheere-Terpstra test. The results are depicted as boxplots in Fig. 4.

We could observe a significant downward trend for the median daily DEHTP intakes with increasing age $\left(\mathrm{p}=0.014^{*}\right.$, level of significance $\alpha=0.05$ ). The youngest children (median DI $1.7 \mu \mathrm{g} / \mathrm{kg}$ bw/d) had $>4$ fold higher daily DEHTP intakes compared to the older children (median DI $0.4 \mu \mathrm{g} / \mathrm{kg} \mathrm{bw} / \mathrm{d}$ ). This, again, points to contaminated foodstuff as a major source of DEHTP exposure, because young children have an increased food intake per kg body weight. Similar findings on age dependent plasticizer exposure have already been reported for DEHP and other plasticizers (Fromme et al., 2007, 2013, Koch and Angerer, 2007, Wittassek et al., 2007).

Higher plasticizer exposures in young children might additionally be caused by other age dependent characteristics, like mouthing of toys and playing near the ground leading to increased dust intake (Moya et al., 2004, Sathyanarayana, 2008, Lee et al., 2014, Ginsberg et al., 2016). Biedermann-Brem et al. (2008) determined plasticizers in $>250$ toys and could detect DEHTP in $10 \%$ of all samples analyzed. Another study investigated the mass content of alternative plasticizers in toys and childcare articles and found DEHTP to be the most frequently used plasticizer with contents of up to 25\% DEHTP relatively to PVC (Xie et al., 2016). In 953 dust samples, collected in German households 
Table 3

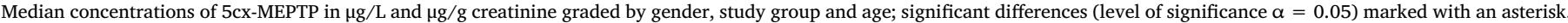

\begin{tabular}{|c|c|c|c|c|c|c|}
\hline & \multicolumn{2}{|l|}{ Gender } & \multicolumn{2}{|l|}{ Study group } & \multicolumn{2}{|l|}{ Age } \\
\hline & Boys $(n=52)$ & Girls $(n=55)$ & $\begin{array}{l}\text { Normal-/underweight, } \\
\text { usual diet }(\mathrm{n}=39)\end{array}$ & $\begin{array}{l}\text { Overweight/obese, } \\
\text { nutritional guidance }(n=68)\end{array}$ & $\begin{array}{l}4-11 \text { years } \\
(\mathrm{n}=68)\end{array}$ & $12-17$ years $(n=39)$ \\
\hline 5cx-MEPTP median $[\mu \mathrm{g} / \mathrm{L}]$ & 3.73 & 4.19 & 4.99 & 3.04 & 4.03 & 4.61 \\
\hline p-Value (Mann-Whitney- $U$ ) & 0.523 & & $0.043^{*}$ & & 0.761 & \\
\hline $\begin{array}{l}\text { 5cx-MEPTP Median } \\
{[\mu \mathrm{g} / \mathrm{g} \text { creatinine }]}\end{array}$ & 3.86 & 3.94 & 4.74 & 3.03 & 4.77 & 2.51 \\
\hline p-Value (Mann-Whitney- $U$ ) & 0.509 & & $0.029^{*}$ & & $0.024 *$ & \\
\hline
\end{tabular}

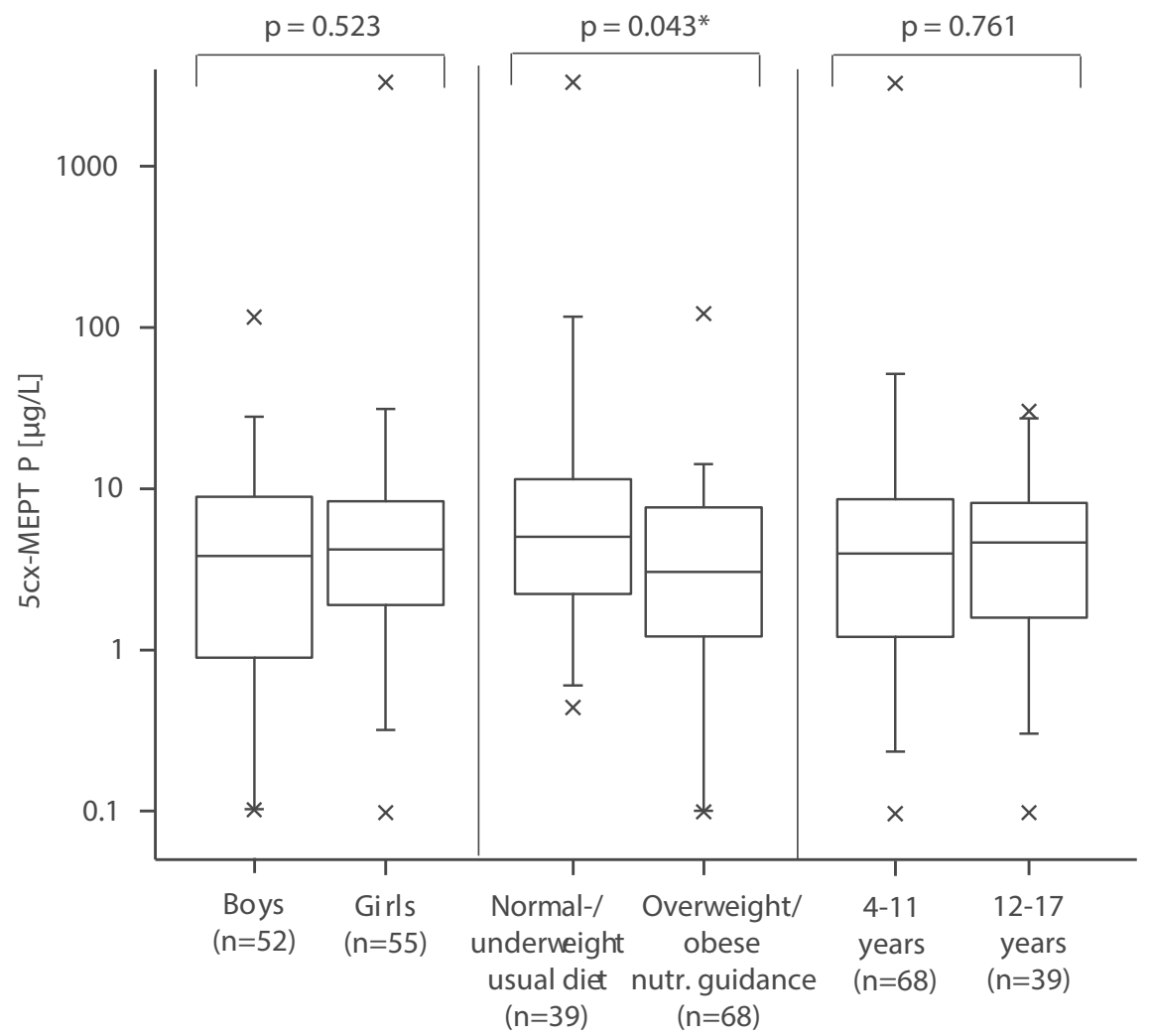

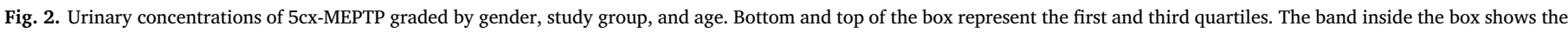

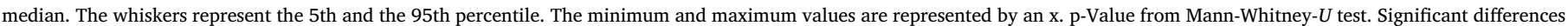
marked with an asterisk.

between 1997 and 2009, Nagorka et al. (2011) reported a rapid increase in DEHTP detection frequencies $(<5 \%$ in the early samples, $94 \%$ in samples of the year 2009) and concentration levels (95th percentile in 2009: $24 \mathrm{mg} / \mathrm{kg}$ ). Fromme et al. (2016) detected DEHTP in all dust samples from 63 German daycare centers for children collected in 2011/2012 with a median concentration of $40 \mathrm{mg} / \mathrm{kg}$ dust. However, they concluded that DEHTP intake by dust ingestion was low compared to tolerable daily intake values even under worst case assumptions.

\subsection{Risk assessment}

For a risk assessment of DEHTP exposure in the Portuguese children, we can either compare urinary metabolite concentrations directly to the Human-Biomonitoring Value (HBM-I value) for DEHTP, a biomarker derived, health based guidance value of the German Human Biomonitoring Commission (Apel et al., 2016), or we can compare the calculated daily intakes to the TDI value of EFSA (2008). The HBM-I

Table 4

Median daily intakes of DEHTP in $\mu \mathrm{g} / \mathrm{kg}$ bw/d graded by gender, study group, and age; significant differences (level of significance $\alpha=0.05$ ) marked with an asterisk.

\begin{tabular}{|c|c|c|c|c|c|c|}
\hline & \multicolumn{2}{|l|}{ Gender } & \multicolumn{2}{|l|}{ Study group } & \multicolumn{2}{|l|}{ Age } \\
\hline & Boys $(n=52)$ & Girls $(n=55)$ & $\begin{array}{l}\text { Normal-/underweight, } \\
\text { usual diet }(\mathrm{n}=39)\end{array}$ & $\begin{array}{l}\text { Overweight/obese, } \\
\text { nutritional guidance }(n=68)\end{array}$ & $\begin{array}{l}4-11 \text { years } \\
(n=68)\end{array}$ & $12-17$ years $(n=39)$ \\
\hline $\begin{array}{l}\text { Daily DEHTP intake } \\
{[\mu \mathrm{g} / \mathrm{kg} \mathrm{bw} / \mathrm{d}]}\end{array}$ & 0.62 & 0.67 & 1.01 & 0.40 & 0.71 & 0.36 \\
\hline $\begin{array}{l}\text { p-Value } \\
\quad \text { (Mann-Whitney- } U \text { ) }\end{array}$ & 0.622 & & $<0.001 *$ & & $0.045^{*}$ & \\
\hline
\end{tabular}




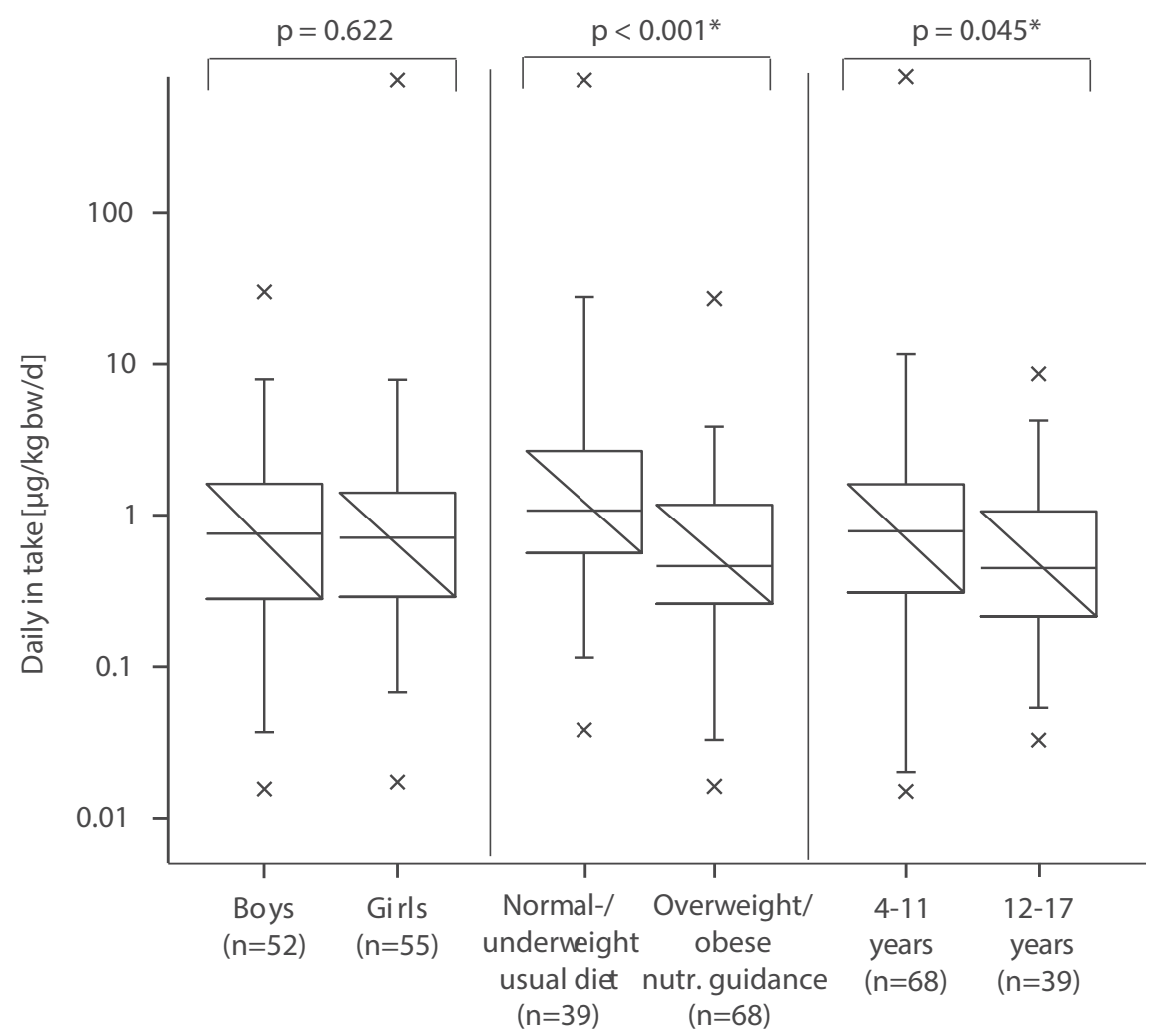

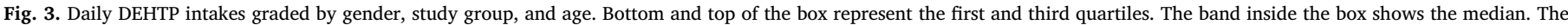

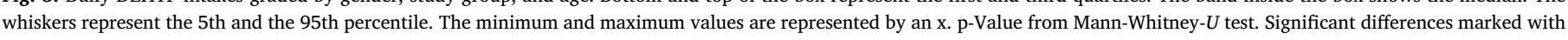
an asterisk.

value describes the concentration of a substance in the body matrix (e.g. urine) below which no adverse health effect should be expected (Angerer et al., 2011). Urinary 5cx-MEPTP concentrations in our study (median $4.19 \mu \mathrm{g} / \mathrm{L}$; 95th percentile $26.4 \mu \mathrm{g} / \mathrm{L}$ ) were considerably below the HBM-I value of $1800 \mu \mathrm{g} / \mathrm{L}$ indicating that detrimental health effects caused by DEHTP are unlikely. However, in one urine sample with a maximum 5cx-MEPTP concentration of $3400 \mu \mathrm{g} / \mathrm{L}$ the HBM-I value was clearly exceeded. The high 5cx-MEPTP concentration in this sample

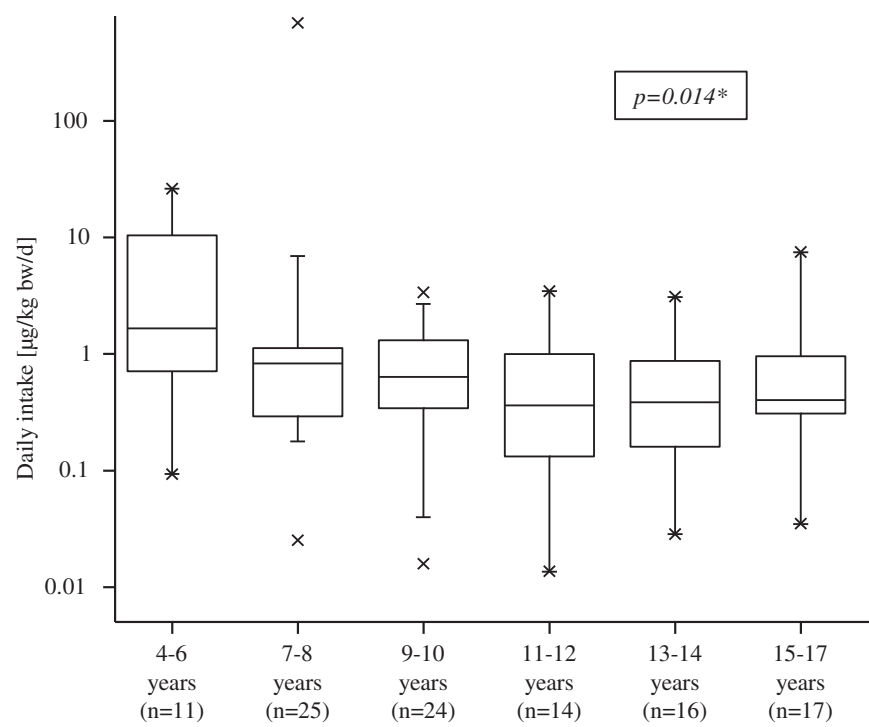

Fig. 4. Daily DEHTP intakes graded by age. Bottom and top of the box represent the first and third quartiles. The band inside the box shows the median. The whiskers represent the 5th and the 95th percentile. The minimum and maximum values are represented by an $\mathrm{x}$; $\mathrm{p}$ value from Jonckheere-Terpstra test. was confirmed by high levels of the other DEHTP metabolites (see Fig. 1), and metabolite ratios were within the range expected from a human metabolism study. Single exceedances of HBM-I values are no reason for immediate concern but should spark repeat sampling (of the respective individual) and verification measurements. If these measurements confirm the initial result an investigation of potential sources of exposure should be undertaken. In the case of this single child, we were not able to obtain a repeat sample.

The TDI for DEHTP is $1000 \mu \mathrm{g} / \mathrm{kg}$ bw/d (EFSA, 2008). For comparison of the daily DEHTP intakes of our study with the TDI of EFSA we calculated the hazard quotient (HQ) defined as the ratio of a daily intake and the respective TDI. HQ values of $>1$ are generally considered a cause of concern. The median daily DEHTP intake in our study for children eating usual diet (group with highest DEHTP exposure) was $1.01 \mu \mathrm{g} / \mathrm{kg}$ bw/d. This daily intake is a factor of 1000 below the TDI, resulting in a HQ of 0.001 . At the 95th percentile of daily intake of about $10 \mu \mathrm{g} / \mathrm{kg}$ bw/d (children eating usual diet) the HQ was 0.01 , again far from the HQ of 1 . The highest calculated daily intake of $690 \mu \mathrm{g} / \mathrm{kg}$ bw/d was also lower than the TDI of $1000 \mu \mathrm{g} /$ $\mathrm{kg} \mathrm{bw} / \mathrm{d}(\mathrm{HQ}=0.69)$. Thus, with regard to the TDI of $1000 \mu \mathrm{g} / \mathrm{kg} \mathrm{bw} /$ $\mathrm{d}$, for none of the investigated children the calculated DEHTP burden poses a toxicological risk. It must be noted that the daily intakes have been calculated based on metabolite levels determined in first morning urine voids as the only specimen available in the study. However, for chemicals like plasticizers with short elimination half-lives and food as a predominant exposure route, this type of sampling might lead to slight underestimations (about up to a factor of 2) since exposures during the day can be missed (Aylward et al., 2011; Lorber et al., 2011; Koch and Angerer, 2012). Another uncertainty in daily intake calculations certainly arises from the assumption of a fixed metabolic conversion factor of 0.13 for 5 cx-MEPTP. This conversion factor has been derived from three adult volunteers and reflects the mean of conversion factors ranging from 0.07 to 0.20 (Lessmann et al., 2016b). While we 
have no indications of metabolic differences between the adults of the metabolism study and the children of our study (very similar metabolite ratios), taking account of the variability observed in the metabolism study, a worst case scenario calculation with the lower end conversion factor of 0.07 would have led to a maximum daily intake of $1280 \mu \mathrm{g}$ / $\mathrm{kg} \mathrm{bw} / \mathrm{d}$.

\section{Conclusion}

The results of the present study for the first time document an omnipresent DEHTP exposure in Portuguese children. Median urinary metabolite levels in this study are approximately 5 times higher than levels found in German adults. These differences are in line with findings for the related plasticizer DEHP, for which children also have higher exposures than adults and for which exposure in Portugal has been reported to be slightly higher than in Germany.

As for other high molecular weight plasticizers, diet seems to be the dominant route of exposure to DEHTP. We could show that children who received specific nutritional guidance with predominately fresh and unprocessed food had about 2.5 fold lower daily intakes than children on a usual diet. Other, child specific sources of exposure might be DEHTP containing toys or house dust. The complex nature of the original study design, however, demands caution and adds some uncertainty to these findings, because body weight status and nutritional characteristics were combined in a manner that is probably reciprocal to the real-life scenario. Unfortunately, we were not able to obtain urine samples collected before, or at the onset of the dietary intervention.

Urinary metabolite data indicate that current exposures to DEHTP both at the median and the upper bounds (95th percentile) are well below health based limit values such as the HBM-I value or the TDI (factor of 1000 at the median and factor of 100 at the 95th percentile). However, for one child we detected DEHTP exposure close to the TDI and exceeding the HBM-I value.

DEHTP is the second ortho-phthalate substitute (after DINCH) for which we could prove the omnipresent exposure of the general population by means of human biomonitoring. As already shown for DINCH (Schütze et al., 2014), we also have to expect a rise in exposure to DEHTP, with predicted consumption numbers doubling from 2012 to 2018. Future studies should therefore closely follow the time course of DEHTP exposure. Such timely exposure assessments in combination with risk assessments will enable us to verify a successful substitution of critical phthalates with alternatives of a preferred toxicological profile. Such exposure assessments will also enable us to intervene and advise regulatory measures, if exposures to the alternatives approach limit values, or if toxicological re-evaluations result in the lowering of these limit values.

\section{Compliance with ethical standards}

The study design was in accordance with the ethical standards of the institutional and/or national research committee and with the 1964 Helsinki declaration and its later amendments or comparable ethical standards. Approval for the study protocol was obtained from the Ethics Commission of the Faculty of Medicine of Oporto University, Portugal (ref. 163.13). Written informed consent was obtained from all parents of individual participants included in the study.

\section{Conflict of interest}

The authors claim, that they do not have any conflict of interest.

This research did not receive any specific grant from funding agencies in the public, commercial, or non-profit sectors.

\section{Acknowledgements}

Luísa Correia-Sá is grateful for the doc fellowship financed by FCT (SFRH/BD/87019/2012).

\section{References}

Ackerman, et al., 2014. Temporal variability of urinary di(2-ethylhexyl) phthalate metabolites during a dietary intervention study. J. Expo. Sci. Environ. Epidemiol. 24 (6), 595-601. http://dx.doi.org/10.1038/jes.2013.93.

Angerer, et al., 2011. Human biomonitoring assessment values: approaches and data requirements. Int. J. Hyg. Environ. Health 214 (5), 348-360. http://dx.doi.org/10. 1016/j.ijheh.2011.06.002

Apel, et al., 2016. New HBM values for emerging substances, inventory of reference and HBM values in force and working principles of the German Human Biomonitoring Commission. Int. J. Hyg. Environ. Health. http://dx.doi.org/10.1016/j.ijheh.2016. 09.007.

Aylward, L.L., Lorber, M., Hays, S.M., 2011. Urinary DEHP metabolites and fasting time in NHANES. J. Expo. Sci. Environ. Epidemiol. 21, 615-624. http://dx.doi.org/10. 1038/jes.2011.28.

Barber, E.D., Topping, D.C., 1995. Subchronic 90-day oral toxicology of di(2-ethylhexyl) terephthalate in the rat. Food Chem. Toxicol. 33 (11), 971-978. http://dx.doi.org/ 10.1016/0278-6915(95)00060-F.

Barr, et al., 2003. Assessing human exposure to phthalates using monoesters and their oxidized metabolites as biomarkers. Environ. Health Perspect. 111 (9), 1148-1151.

Barr, et al., 2005. Urinary creatinine concentration in the U.S. population: implications for urinary biologic monitoring measurements. Environ. Health Perspect. 113, 192-200. http://dx.doi.org/10.1289/ehp.7337.

Biedermann-Brem, et al., 2008. Plasticizers in PVC toys and childcare products: what succeeds the phthalates? Market survey 2007. Chromatographia 68, 227. http://dx doi.org/10.1365/s10337-008-0672-9.

Boberg, et al., 2011. Reproductive and behavioral effects of diisononyl phthalate (DINP) in perinatally exposed rats. Reprod. Toxicol. 31 (2), 200-209. http://dx.doi.org/10. 1016/j.reprotox.2010.11.001.

Buser, M.C., Murray, H.E., Scinicariello, F., 2014. Age and sex differences in childhood and adulthood obesity association with phthalates: analyses of NHANES 2007-2010. Int. J. Hyg. Environ. Health 217 (6), 687-694. http://dx.doi.org/10.1016/j.ijheh. 2014.02.005.

Černá, et al., 2015. Case study: possible differences in phthalates exposure among the Czech, Hungarian, and Slovak populations identified based on the DEMOCOPHES pilot study results. Environ. Res. 141, 118-124. http://dx.doi.org/10.1016/j.envres. 2014.10.025.

Cutanda, et al., 2015. Urinary levels of eight phthalate metabolites and bisphenol A in mother-child pairs from two Spanish locations. Int. J. Hyg. Environ. Health 218 (1) 47-57. http://dx.doi.org/10.1016/j.ijheh.2014.07.005.

David, R.M., 2000. Exposure to phthalate esters. Environ. Health Perspect. 108 (10), A440.

Den Hond, et al., 2015. First steps toward harmonized human biomonitoring in Europe: demonstration project to perform human biomonitoring on a European scale. Environ. Health Perspect. 123 (3), 255-263. http://dx.doi.org/10.1289/ehp. 1408616.

Deyo, J.A., 2008. Carcinogenicity and chronic toxicity of di-2-ethylheyl terephthalate (DEHT) following a 2-year dietary exposure in Fischer 344 rats. Food Chem. Toxicol. 46 (3), 990-1005. http://dx.doi.org/10.1016/j.fct.2007.10.037.

European Food Safety Authority, 2008. Opinion of the scientific panel on food additives, flavourings, processing aids and materials in contact with food (AFC) on a request related to a 18th list of substances for food contact materials. Question $\mathrm{N}^{\circ}$ EFSA-Q2007-167, EFSA-Q-2006-177, EFSA-Q-2005-152, EFSA-Q-2007-022, EFSA-Q-2007004, EFSA-Q-2007-024. EFSA J. 628-633, 1-19.

Foster, P.M.D., 2006. Disruption of reproductive development in male rat offspring following in utero exposure to phthalate esters. Int. J. Androl. 29 (1), 140-147. http://dx.doi.org/10.1111/j.1365-2605.2005.00563.x.

Frederiksen, et al., 2013. Urinary excretion of phthalate metabolites, phenols and parabens in rural and urban Danish mother-child pairs. Int. J. Hyg. Environ. Health 216 (6), 772-783. http://dx.doi.org/10.1016/j.ijheh.2013.02.006.

Fromme, et al., 2007. Intake of phthalates and di(2-ethylhexyl)adipate: results of the Integrated Exposure Assessment Survey based on duplicate diet samples and biomonitoring data. Environ. Int. 33 (8), 1012-1020. http://dx.doi.org/10.1016/j. envint.2007.05.006.

Fromme, et al., 2013. Phthalates in German daycare centers: occurrence in air and dust and the excretion of their metabolites by children (LUPE 3). Environ. Int. 61, 64-72. http://dx.doi.org/10.1016/j.envint.2013.09.006.

Fromme, et al., 2016. Non-phthalate plasticizers in German daycare centers and human biomonitoring of DINCH metabolites in children attending the centers (LUPE 3). Int J. Hyg. Environ. Health 219 (1), 33-39. http://dx.doi.org/10.1016/j.ijheh.2015.08. 002 .

Furr, et al., 2014. A short-term in vivo screen using fetal testosterone production, a key event in the phthalate adverse outcome pathway, to predict disruption of sexual differentiation. Toxicol. Sci. 140 (2), 403-424. http://dx.doi.org/10.1093/toxsci/ kfu081.

Ginsberg, G., Ginsberg, J., Foos, B., 2016. Approaches to children's exposure assessment: case study with diethylhexylphthalate (DEHP). Int. J. Environ. Res. Public Health 1, 13(7). http://dx.doi.org/10.3390/ijerph13070670.

Gray, et al., 2000. Perinatal exposure to the phthalates DEHP, BBP, and DINP but not 
DEP, DMP or DOTP, alters sexual differentiation of the male rat. Toxicol. Sci. 58 (2), 350-365.

Hornung, R.W., Reed, L.D., 1990. Estimation of average concentration in the presence of nondetectable values. Appl. Occup. Environ. Hyg. 5, 46-51. http://dx.doi.org/10. 1080/1047322X.1990.10389587.

Hou, et al., 2015. The effects of phthalate and nonylphenol exposure on body size and secondary sexual characteristics during puberty. Int. J. Hyg. Environ. Health 218 (7), 603-615. http://dx.doi.org/10.1016/j.ijheh.2015.06.004.

ICH, 2000. Harmonised tripartite guideline: clinical investigation of medicinal products in the paediatric population. http://www.ich.org/products/guidelines/efficacy/ efficacy-single/article/clinical-investigation-of-medicinal-products-in-the-pediatricpopulation.html.

Jaffe, M.Z., 1886. About the precipitation caused by pikrinic acid in normal urine and about a new reaction of creatinine. Physiol. Chem. 10, 391-400.

Jonckheere, A.R., 1954. A distribution-free k-sample test against ordered alternatives. Biometrika 41 (1/2), 133-145.

Kasper-Sonnenberg, et al., 2014. Phthalate metabolites and bisphenol A in urines from German school-aged children: results of the Duisburg birth cohort and Bochum cohort studies. Int. J. Hyg. Environ. Health 217 (8), 830-838. http://dx.doi.org/10. 1016/j.ijheh.2014.06.001.

Kilcoyne, et al., 2014. Fetal programming of adult Leydig cell function by androgenic effects on stem/progenitor cells. Proc. Natl. Acad. Sci. U. S. A. 6 (111(18)), E1924-E1932. http://dx.doi.org/10.1073/pnas.1320735111.

Kim, et al., 2016. Association of diethylhexyl phthalate with obesity-related markers and body mass change from birth to 3 months of age. J. Epidemiol. Community Health 70 (5), 466-472. http://dx.doi.org/10.1136/jech-2015-206315.

Koch, H.M., Angerer, J., 2007. Di-iso-nonylphthalate (DINP) metabolites in human urine after single oral dose of deuterium-labelled DINP. Int. J. Hyg. Environ. Health 210 (1), 9-19. http://dx.doi.org/10.1016/j.ijheh.2006.11.008.

Koch, H.M., Angerer, J., 2012. Chapter 3A phthalates: biomarkers and human biomonitoring. In: Biomarkers and Human Biomonitoring. vol. 1 The Royal Society of Chemistry.

Koch, H.M., Drexler, H., Angerer, J., 2003a. An estimation of the daily intake of di(2ethylhexyl)phthalate (DEHP) and other phthalates in the general population. Int. J. Hyg. Environ. Health 206 (2), 77-83.

Koch, H.M., Gonzalez-Reche, L.M., Angerer, J., 2003b. On-line clean-up by multidimensional liquid chromatography electrospray ionization tandem mass spectrometry for high throughput quantification of primary and secondary pththalate metabolites in human urine. J. Chromatogr. B 784 (1), 169-182. http://dx.doi.org/ $10.1016 /$ S1570-0232(02)00785-7.

Koch, et al., 2004. Exposure of nursery school children and their parents and teachers to di-n-butylphthalate and butylbenzylphthalate. Int. Arch. Occup. Environ. Health 78 (3), 223-229. http://dx.doi.org/10.1007/s00420-004-0570-x.

Koch, et al., 2005. Di(2-ethylhexyl)phthalate (DEHP) exposure of voluntary plasma and platelet donors. Int. J. Hyg. Environ. Health 208 (6), 489-498. http://dx.doi.org/10. 1016/j.ijheh.2005.07.001.

Koch, et al., 2013a. Identifying sources of phthalate exposure with human biomonitoring: results of a $48 \mathrm{~h}$ fasting study with urine collection and personal activity patterns. Int. J. Hyg. Environ. Health 216 (6), 672-681. http://dx.doi.org/10.1016/j.ijheh.2012. 12.002.

Koch, et al., 2013b. Metabolism of the plasticizer and phthalate substitute diisononylcyclohexane-1,2-dicarboxylate (DINCH) in humans after single oral doses. Arch. Toxicol. 87 (5), 799-806. http://dx.doi.org/10.1007/s00204-012-0990-4.

Kohn, et al., 2000. Human exposure estimates for phthtalates. Environ. Health Perspect. 108 (10), A440-A442.

Lee, et al., 2014. Childhood exposure to DEHP, DBP and BBP under existing chemical management systems: a comparative study of sources of childhood exposure in Korea and in Denmark. Environ. Int. 63, 77-91. http://dx.doi.org/10.1016/j.envint.2013. 10.020 .

Lessmann, et al., 2016a. Determination of metabolites of di(2-ethylhexyl) terephthalate (DEHTP) in human urine by HPLC-MS/MS with on-line clean-up. J. Chromatogr. B 1011, 196-203. http://dx.doi.org/10.1016/j.jchromb.2015.12.042.

Lessmann, et al., 2016b. Metabolism and urinary excretion kinetics of di(2-ethylhexyl) terephthalate (DEHTP) in three male volunteers after oral dosage. Arch. Toxicol. 90 (7), 1659-1667. http://dx.doi.org/10.1007/s00204-016-1715-x.

Lorber, M., Koch, H.M., Angerer, J., 2011. A critical evaluation of the creatinine correction approach: can it underestimate intakes of phthalates? A case study with di2-ethylhexyl phthalate. J. Expo. Sci. Environ. Epidemiol. 21, 576-586. http://dx.doi. org/10.1038/jes.2010.43.

Malveda, et al., 2015. Chemical Economics Handbook Plasticizers. IHS Global Inc.
Mervish, et al., 2014. Dietary predictors of urinary environmental biomarkers in young girls, BCERP, 2004-7. Environ. Res. 133, 12-19. http://dx.doi.org/10.1016/j.envres. 2014.04.040.

Moya, J., Bearer, C.F., Etzel, R.A., 2004. Children's behavior and physiology and how it affects exposure to environmental contaminants. Pediatrics 113 (4 Suppl), 996-1006.

Myridakis, et al., 2015. Phthalate esters, parabens and bisphenol-A exposure among mothers and their children in Greece (Rhea cohort). Environ. Int. 83, 1-10. http://dx. doi.org/10.1016/j.envint.2015.05.014.

Nagorka, et al., 2011. Diisononyl 1,2-cyclohexanedicarboxylic acid (DINCH) and di(2ethylhexyl) terephthalate (DEHT) in indoor dust samples: concentration and analytical problems. Int. J. Hyg. Environ. Health 214 (1), 26-35. http://dx.doi.org/ 10.1016/j.ijheh.2010.08.005.

Remer, T., Neubert, A., Maser-Gluth, C., 2002. Anthropometry-based reference values for 24-h urinary creatinine excretion during growth and their use in endocrine and nutritional research. Am. J. Clin. Nutr. 75 (3), 561-569.

Rudel, et al., 2011. Food packaging and bisphenol A and bis(2-ethyhexyl) phthalate exposure: findings from a dietary intervention. Environ. Health Perspect. 119 (7), 914-920. http://dx.doi.org/10.1289/ehp.1003170.

Sathyanarayana, S., 2008. Phthalates and children's health. Curr. Probl. Pediatr. Adolesc. Health Care 38 (2), 34-49. http://dx.doi.org/10.1016/j.cppeds.2007.11.001.

Sathyanarayana, et al., 2013. Unexpected results in a randomized dietary trial to reduce phthalate and bisphenol A exposures. J. Expo. Sci. Environ. Epidemiol. 23 (4), 378-384. http://dx.doi.org/10.1038/jes.2013.9.

Schütze, et al., 2012. Quantification of biomarkers of environmental exposure to di (isononyl)cyclohexane-1,2-dicarboxylate (DINCH) in urine via HPLC-MS/MS. J. Chromatogr. B 1 (895-896), 123-130. http://dx.doi.org/10.1016/j.jchromb.2012. 03.030 .

Schütze, et al., 2014. Entering markets and bodies: increasing levels of the novel plasticizer Hexamoll ${ }^{\circledast}$ DINCH $^{\circledast}$ in 24 h urine samples from the German Environmental Specimen Bank. Int. J. Hyg. Environ. Health 217 (2-3), 421-426. http://dx.doi.org/ 10.1016/j.ijheh.2013.08.004.

Schütze, et al., 2017. Additional oxidized and alkyl chain breakdown metabolites of the plasticizer DINCH in urine after oral dosage to human volunteers. Arch. Toxicol. 91 (1), 179-188. http://dx.doi.org/10.1007/s00204-016-1688-9.

Silva, et al., 2003. Glucuronidation patterns of common urinary and serum monoester pththalate metabolites. Arch. Toxicol. 77 (10), 561-567. http://dx.doi.org/10.1007/ s00204-003-0486-3.

The European Commission, 2011. Commission Regulation (EU) No 10/2011 of 14 January 2011 on Plastic Materials and Articles Intended to Come Into Contact With Food. Official Journal L 012 15.1.2011. pp. 1 (Consolidated text of 24 August 2016).

The European Parliament, 2006. Regulation (EC) No 1907/2006 of the European Parliament and of the Council of 18 December 2006 Concerning the Registration, Evaluation, Authorisation and Restriction of Chemicals (REACH), Establishing a European Chemicals Agency, Amending Directive 1999/45/EC and Repealing Council Regulation (EEC) No 793/93 and Commission Regulation (EC) No 1488/94 as well as Council Directive 76/769/EEC and Commission Directives 91/155/EEC, 93/67/EEC, 93/105/EC and 2000/21/EC., Official Journal L 396 30/12/2006. pp. 1 (Consolidated text of 5 September 2015).

The European Parliament, 2008. Regulation (EC) No 1272/2008 of the European Parliament and of the Council of 16 December 2008 on Classification, Labelling and Packaging of Substances and Mixtures, Amending and Repealing Directives 67/548/ EEC and 1999/45/EC, and Amending Regulation (EC) No 1907/2006. Official Journal L 353, 31/12/2008 P. 0001-1355. (Consolidated text of 06 December 2014).

Topping, et al., 1987. Peroxisome induction studies on di(2-ethylhexyl)terephthalate. Toxicol. Ind. Health 3 (2), 63-78.

Trasande, et al., 2013. Phthalates and the diets of U.S. children and adolescents. Environ. Res. 126, 84-90. http://dx.doi.org/10.1016/j.envres.2013.07.007.

WHO, 2007. Growth reference 5-19 years - Body mass index. http://www.who.int/ growthref/who2007_bmi_for_age/en/.

Wittassek, et al., 2007. Daily intake of di(2-ethylhexyl)phthalate (DEHP) by German children - a comparison of two estimation models based on urinary DEHP metabolite levels. Int. J. Hyg. Environ. Health 210 (1), 35-42. http://dx.doi.org/10.1016/j. ijheh.2006.11.009.

Xie, et al., 2016. Phthalates and alternative plasticizers and potential for contact exposure from children's backpacks and toys. J. Expo. Sci. Environ. Epidemiol. 26 (1), 119-124. http://dx.doi.org/10.1038/jes.2015.71.

Yaghjyan, et al., 2015. Associations of urinary phthalates with body mass index, wais circumference and serum lipids among females: National Health and Nutrition Examination Survey 1999-2004. Int. J. Obes. 39 (6), 994-1000. http://dx.doi.org/ 10.1038/ijo.2015.8. 